\section{(6) OPEN ACCESS}

\title{
The effect of reduced street lighting on road casualties and crime in England and Wales: controlled interrupted time series analysis
}

\author{
Rebecca Steinbach, ${ }^{1}$ Chloe Perkins, ${ }^{2}$ Lisa Tompson, ${ }^{3}$ Shane Johnson, ${ }^{3}$ \\ Ben Armstrong, ${ }^{1}$ Judith Green, ${ }^{4}$ Chris Grundy, ${ }^{1}$ Paul Wilkinson, ${ }^{1}$ Phil Edwards ${ }^{2}$
}

\begin{abstract}
- Additional material is published online only. To view please visit the journal online (http://dx.doi.org/10.1136/jech2015-206012)

${ }^{1}$ Department of Social and Environmental Health Research, London School of Hygiene \& Tropical Medicine, London, UK ${ }^{2}$ Department of Population Health, London School of Hygiene \& Tropical Medicine, London, UK

${ }^{3}$ Department of Security and Crime Science, University College London, London, UK ${ }^{4}$ Department of Health Services Research, London School of Hygiene \& Tropical Medicine, London, UK
\end{abstract}

\section{Correspondence to} Dr Phil Edwards, Department of Population Health, London School of Hygiene \& Tropical Medicine, Keppel Street, London WC1E 7HT, UK: Phil.Edwards@|shtm.ac.uk

Received 6 May 2015 Revised 2 June 2015 Accepted 3 June 2015 Published Online First 29 July 2015

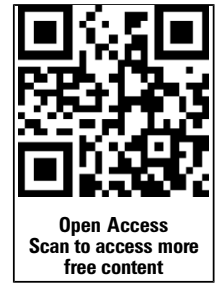

\section{CrossMark}

To cite: Steinbach $R$ Perkins C, Tompson L, et al. J Epidemiol Community Health 2015;69:11181124.

\section{ABSTRACT}

Background Many local authorities in England and Wales have reduced street lighting at night to save money and reduce carbon emissions. There is no evidence to date on whether these reductions impact on public health. We quantified the effect of 4 street lighting adaptation strategies (switch off, part-night lighting, dimming and white light) on casualties and crime in England and Wales.

Methods Observational study based on analysis of geographically coded police data on road traffic collisions and crime in 62 local authorities. Conditional Poisson models were used to analyse longitudinal changes in the counts of night-time collisions occurring on affected roads during 2000-2013, and crime within census Middle Super Output Areas during 2010-2013. Effect estimates were adjusted for regional temporal trends in casualties and crime.

Results There was no evidence that any street lighting adaptation strategy was associated with a change in collisions at night. There was significant statistical heterogeneity in the effects on crime estimated at police force level. Overall, there was no evidence for an association between the aggregate count of crime and switch off (RR $0.11 ; 95 \% \mathrm{Cl} 0.01$ to 2.75) or part-night lighting (RR 0.96; $95 \% \mathrm{Cl} 0.86$ to 1.06). There was weak evidence for a reduction in the aggregate count of crime and dimming (RR $0.84 ; 95 \% \mathrm{Cl} 0.70$ to 1.02 ) and white light (RR $0.89 ; 95 \% \mathrm{Cl} 0.77$ to 1.03 ).

Conclusions This study found little evidence of harmful effects of switch off, part-night lighting, dimming, or changes to white light/LEDs on road collisions or crime in England and Wales.

\section{INTRODUCTION}

Within a context of cost constraints and increasing local accountability for climate change mitigation, technological innovation is enabling changes to the provision of street lighting in England and Wales in ways that may have important implications for public health. Emerging technologies, such as LED lighting and computerised central management systems, have created opportunities for local authorities to adapt their street lighting strategies in ways that can reduce energy costs and contribute to reductions in carbon emissions. However, there is also concern that reductions in street light at night might increase road traffic injury, crime and fear of crime.

Local authorities are able to draw on national guidance on lighting ${ }^{1}$ and professional standards ${ }^{2}$ when making decisions about street lighting, but ultimately make their own assessment of the most appropriate lighting regime on each road for which they have responsibility. Three street light adaptation strategies reduce the amount of light: switching lights off permanently ('switch off'), reducing the number of hours that lamps are switched on at night ('part-night' lighting), and reducing the power or output of lamps ('dimming'). A fourth strategy is to replace traditional sodium lamps (orange/yellow light) with more energy efficient lamps or LEDs ('white light').

Each of these strategies has prompted public and media concerns about the negative effects that focus on risks of night-time road traffic collisions, crime, and fear of crime. ${ }^{3}$ Road collisions have received particular attention, with a number of coroners concluding that reduced street lighting contributed to road deaths sparking inquests. ${ }^{4}$ However, health and well-being benefits from reduced light pollution (eg, improved sleep and being able to see the night sky) have also been noted. ${ }^{5}{ }^{6}$ There are also putative benefits from reductions in artificial light at night, which have been linked to a range of health outcomes affected by disruptions to the circadian rhythms. ${ }^{7-9}$

Public concern that street lighting is necessary for road safety and crime prevention is, in part, supported by the literature: systematic reviews have identified some evidence for improved road safety ${ }^{10}$ and an overall reduction in crime ${ }^{11}$ with increased street lighting. However, with respect to crime, studies show that reductions in victimisation are observed during both hours of daylight and darkness, ${ }^{11}$ calling into question the mechanism through which improvements to street lighting might influence crime. Moreover, there is to date, no empirical evidence on whether the implementation of reduced street lighting has had any negative effects on these important public health outcomes. National research on the effects of reduced street lighting on road traffic collisions and crime is, therefore, timely.

Theoretically, street light adaptation strategies might influence the risk of road traffic collisions and crime in a number of ways. Reducing lighting levels by switch off, part-night lighting, or dimming can reduce visibility in an area, which may increase the risk of collisions if road users are no longer able to detect hazards. Reduced visibility may also decrease mobility if fear of collisions, falling over in the dark, or fear of crime deters people from making some journeys. Fewer people on the streets might reduce road casualties by reducing the 
potential for collisions, but may decrease the 'natural surveillance' in an area, leading to an increase in crime. Reduced visibility may also reduce crime, such as theft from vehicles or robbery, if criminals are less able to identify potential targets. The introduction of energy efficient lamps, or LEDs, can change the quality and colour of lighting (eg, from yellow to white light) without reducing visibility. White light might improve visual acuity, and by improving closed circuit television (CCTV) images can make criminals feel more conspicuous, thus deterring certain types of crime.

The broader cultural meanings of street lighting as one component of modern (sub)urban life may also link switch off, part-night lighting and dimming strategies to crime. Residents and visitors may feel that areas targeted for lighting reductions have been devalued; this may lower levels of community pride, leading to behavioural changes that influence crime. Alternatively, introducing new technologies, such as white light/ LEDs, in an area may signal increased investment in a community to local residents, which may increase community pride and a willingness to use, and to monitor, their neighbourhood, leading to a reduction in crime.

In summary, street light adaptation strategies may have different effects on two public health outcomes, casualties and crime. In light of a lack of evidence, we used the reduction of street lighting by local authorities in England and Wales as a natural experiment to examine whether it was associated with any changes in road traffic collisions and crime. The project was called the LANTERNS (Local Authority collaborators' National Evaluation of Reduced Night-time Streetlight) project.

\section{METHODS}

We designed a controlled interrupted time series analysis to examine associations between reduced street lighting and road traffic collisions and crime, adjusting for regional trends. Analyses were conducted at road level for traffic collisions and at area level for crime. Analyses were based on the patterns of change in monthly counts of collisions and crimes within each street, or area.

\section{Data sources}

Street lighting - all local authorities in England and Wales were invited to participate in the study (details of recruitment methods are reported elsewhere). ${ }^{3}$ From local authorities who had made changes to street lighting provision at night, data were requested on the geographic location of each street lighting column, the change to lighting (eg, part-night lighting), and the date the change was introduced. All local authorities who provided usable data by October 2014 were included in the analysis.

Traffic collisions-data on traffic collisions were obtained from STATS19, the official dataset of collisions on public highways in the UK collected by the police. Data were obtained on the dates, times, geographical coordinates of collision locations, and severity of casualties for all collisions that occurred during the period 2000-2013.

Crime-data on crime were obtained from the Police.uk website from December 2010 (the earliest date for which the data are available) to December 2013. Data included type of crime, year, month, name of road where the crime occurred, and approximate geographical coordinates.

\section{Exposure variables}

Street lighting —-data were linked using a geographical information system (GIS) to a detailed road segment database derived from the Ordnance Survey Mastermap Integrated Transport Network. ${ }^{12}$ For each month between January 2000 and December 2013, road segments were categorised according to whether switch off, part-night lighting, dimming and white light had been implemented in the lighting columns along that segment. Where combinations of interventions had been implemented (eg, part-night lighting with white light), road segments were categorised as having both interventions. To facilitate arealevel analyses, we also calculated the proportion of total kilometres of road in each area that had introduced switch off, partnight lighting, dimming and white light.

\section{Outcome variables}

Traffic collisions-collisions recorded in STATS19 were classified as 'night-time' (occurring between sunset and sunrise) or 'day-time' (between sunrise and sunset) according to the time and date of the collision. For this, we obtained the daily timings of sunrise and sunset in each region of England and Wales between 1 January 2000 and 31 December 2013. Using data on injury severity, we classified each collision according to whether any casualties suffered a fatal or serious injury. A casualty is classified as fatal if the person dies within 30 days of the collision. A casualty is defined as serious if the person is admitted to hospital or has suffered fractures, concussion, internal injuries, crushing, non-friction burns, severe cuts and lacerations, or is in severe general shock requiring medical treatment. A GIS was used to link collisions to road segments using a combination of spatial overlay and analysis of the text descriptor of each road location. In brief, the algorithm assigned a collision to the nearest road segment of the type indicated in the STATS19 report. Collisions occurring over $50 \mathrm{~m}$ from a road segment of the appropriate type were excluded from analysis. We calculated counts of collisions in road segments for each month from January 2000 to December 2013.

Crime-to preserve victim anonymity, the publicly available Police.uk data only includes approximate geographical coordinates of offences, and does not detail the time of day of offences. A study of the spatial accuracy of the data suggests that it is very good for large areal units, such as census Middle Super Output Areas (MSOA), that contain around 7500 people, ${ }^{13}$ but not for the postcode or street segment level. We therefore analysed crime at the MSOA level, assigning each offence to the relevant MSOA. We analysed offences most likely to occur during the evening or at night: burglary, theft of (or from) a vehicle, robbery, criminal damage, and violence, including sexual assault. ${ }^{14}$ We calculated counts of each offence in MSOAs for each month from December 2010 to December 2013.

\section{Statistical methods}

Our focus was to characterise the influence of changes in street lighting on collisions and crime after allowing for underlying trends over time. Analyses were based on the patterns of change in the monthly counts of collisions within each road segment, and in the monthly counts of crime within each MSOA. To control for confounding due to differences in areas chosen and not chosen for interventions, we analysed these road level (collision) and MSOA level (crime) counts as 'panel' studies, conditional on total counts in each road or MSOA, such that any of the factors that are constant over time (eg, road design) contribute no information to the analysis. Conditional Poisson regression models were used rather than standard Poisson models to allow variation in rates by road segment and MSOA without having to directly estimate a large number of nuisance parameters. ${ }^{15}$ Further details of the models are given in web 
appendix 1. We conducted sensitivity analyses by assuming a negative binomial, rather than Poisson model, by allowing for zero inflation and by fitting models without autoregression terms.

Traffic collisions-We estimated the association of each street lighting adaptation intervention with night-time collisions from a single model to avoid mutual confounding. To guard against bias due to changes concurrent with lighting interventions that impact on overall (ie, day and night) collisions, the data set included counts of daytime collisions and a binary variable indicating day/night. We estimated from our regression model the change in collision rate associated with each street lighting adaptation intervention during daytime as well as night-time, and the ratio of night-time and daytime changes. We consider this 'daytime collision' adjusted measure the most robust estimate of the change in night-time collisions following the lighting intervention. Models were adjusted for seasonal variation and temporal trends by fitting individual terms for year and month. Models were fitted for each region in England and Wales, and effect estimates were pooled in a fixed effects meta-analysis.

Crime-we estimated the association between changes in the proportion of total kilometres of road in each MSOA that had introduced each street lighting adaptation intervention, and counts of each criminal offence (and their aggregation), controlling for trends in crime over time. We fitted indicator variables for the number of months elapsed from the start of the study (ie, a step function for elapsed month, from December 2010). We fitted separate models for each police force in view of their different data collection systems and evidence for different background time patterns across these systems. We pooled effect estimates in a random effects meta-analysis. Given the large number of police forces and types of crime considered, we do not present forest plots of the meta-analyses in the main text, only the means for England and Wales.

\section{RESULTS}

By October 2014, we had had direct contact with 125 (72\%) of the 174 local authorities in England and Wales, resulting in data submissions from 71 local authorities of which 62 provided usable data (figure 1). Data for nine authorities were excluded due to missing information on dates of changes, and changes implemented after the end of the study. Local authorities from each region provided data. The participating local authorities were evenly distributed across deciles according to population density (persons per hectare), covered the range of deprivation levels as measured by the Index of Multiple Deprivation 2010, and covered each of the six urban-rural classifications of areas.

Street lighting - of the 62 local authorities with usable data, $5(8 \%)$ had introduced switch off, $30(48 \%)$ had introduced part-night lighting, 40 (65\%) had introduced dimming, and 52 $(84 \%)$ had introduced white light. The introduction of street lighting adaptation strategies increased steadily from 2009 (figure 2). By December 2013, the local authorities participating in this study had implemented white light on a total of $15833 \mathrm{~km}$ of road (7\% of total road $\mathrm{km}$ in the 62 participating local authorities); part-night lighting on $12101 \mathrm{~km}$ of road (5\%); dimming on $10519 \mathrm{~km}$ of road (4\%); and switch off on $946 \mathrm{~km}$ of road $(0.4 \%)$. The proportions of total kilometres of road in each MSOA that had lights switched off ranged from $0 \%$ to $60 \%$ (median $0.03 \%$; IQR $0.01-0.05 \%$ ). For part-night lighting, the proportions ranged from 0 to $84 \%$ (median $0.2 \%$; IQR $0.1-18 \%$ ); for dimming, the proportions ranged from 0 to 93\% (median 0.14\%; IQR 0.07-5\%); and for white light,

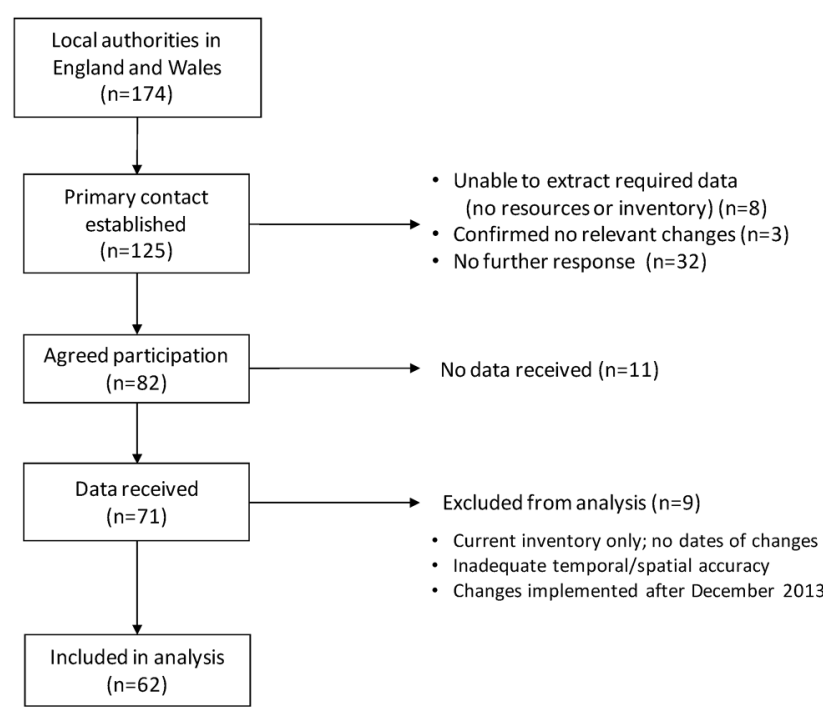

Figure 1 Flow of local authority participants in the LANTERNS project.

the proportions ranged from 0 to $81 \%$ (median $1 \%$; IQR $0.15-11 \%)$.

Traffic collisions-during 2000-2013 there were 859935 collisions in the 62 local authorities included in the analysis; of these, 161049 (19\%) were night-time collisions; 153442 $(18 \%)$ collisions had resulted in a serious injury or fatality. Of the night-time collisions, $1202(0.7 \%)$ occurred on roads along which switch off had been introduced by December 2013; 5670 (4\%) were on roads with part-night lighting; 11634 (7\%) were on roads with dimming; and 12423 (8\%) were on roads with white light.

We found little evidence for any associations between street light adaptation strategies and day-adjusted night-time collision rates (figure 3). There was no evidence from any of the regional models, or the overall estimates, for an association between switch off (rate ratio (RR) $0.97 ; 95 \%$ CI 0.82 to 1.15 ), partnight lighting (RR 0.95 ; 95\% CI 0.84 to 1.07 ); or dimming (RR $1.00 ; 95 \%$ CI 0.91 to 1.10 ). There was weak evidence in London for an association between the introduction of white light and increased night-time collisions (RR 1.30; 95\% CI 1.03 to 1.65); however, the overall national estimate provides no evidence for such an association (RR $1.01 ; 95 \%$ CI 0.93 to 1.09 ).

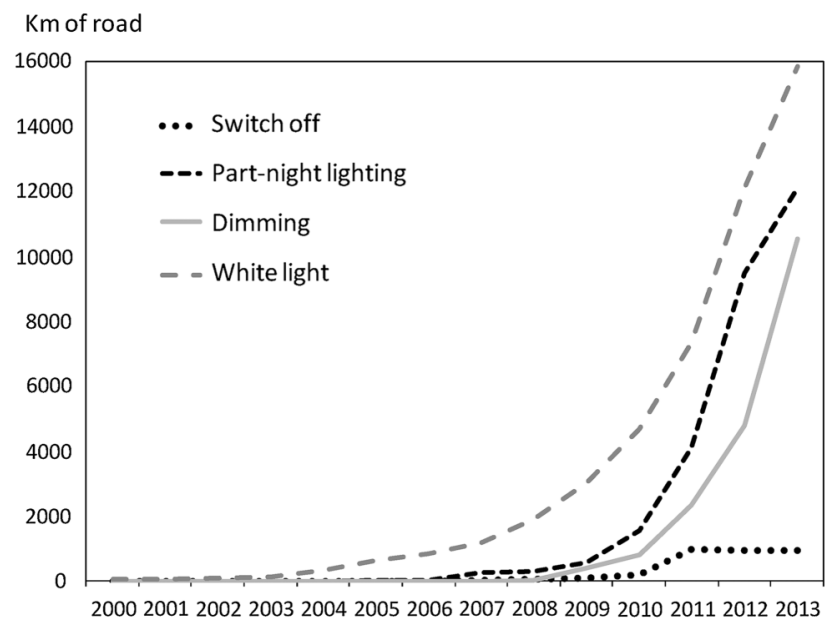

Figure 2 Kilometres of road with lighting adaptation strategies implemented in participating local authorities. 
Road traffic collisions
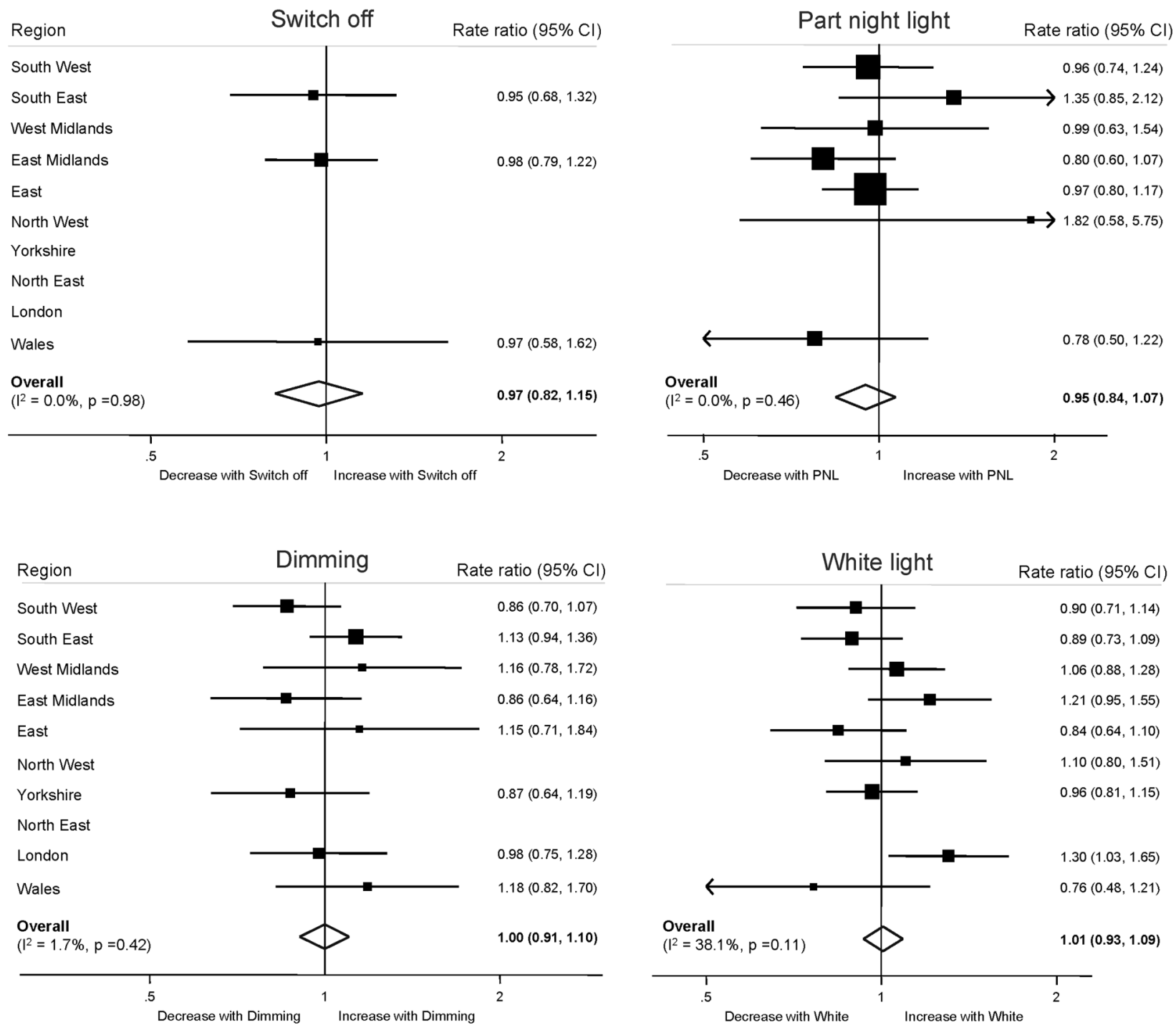

Figure 3 Associations between street light adaptation strategies and night-time road traffic collisions.

Similarly, models estimating associations between street light adaptation strategies and collisions causing a serious injury or fatality found no evidence for associations with any lighting intervention (see web appendix 2).

Crime-across the 62 local authority areas there had been 581837 burglaries; 475657 thefts of or from a vehicle; 67470 robberies; 486367 criminal damage offences and 730280 violence offences during the period December 2010 to December 2013.

Figure 4 shows the estimated mean associations between changes in the proportion of total kilometres of road in each MSOA that had introduced each street lighting adaptation intervention, and counts of each offence across England and Wales. The rate ratios indicate the expected change in crime if $100 \%$ of total kilometres of road in an area were to receive the lighting intervention.

There was no evidence from the overall estimates for an association between the aggregate count of crime and switch off (RR $0.11 ; 95 \%$ CI 0.01 to 2.75 ) or part-night lighting (RR $0.96 ; 95 \%$ CI 0.86 to 1.06 ). There was weak evidence for a reduction in the aggregate count of crime and dimming (RR 0.84 ; 95\% CI 0.70 to 1.02), and white light (RR $0.89 ; 95 \%$ CI 0.77 to 1.03 ). We found significant heterogeneity between the estimates at police force level (see web appendix 3); there was strong evidence for an association between part-night lighting, dimming and white light, and a decrease in crimes in some police forces, and strong evidence for an association between part-night lighting, dimming and white light, and an increase in crimes in others.

When specific offences were considered, the estimates provide suggestive evidence that part-night lighting may be associated with an increase in robbery (RR $1.48 ; 95 \%$ CI 0.99 to 2.21 ), and that dimming may be associated with a decrease in violence (RR 0.78 ; 95\% CI 0.60 to 1.01 ). At the national level, we found consistency in the direction of the estimated associations between crime and dimming, with all point estimates indicating reductions in crime. There was similar consistency in the estimated associations with white light, all suggesting reductions in crime. Again, however, we found substantial statistical heterogeneity between estimates of associations between all lighting adaptations on all crime types at police force level (see web appendix 3).

Small differences were apparent in sensitivity analyses, but the results for collisions and crime were not materially different from the main results. We found no evidence for zero inflation. 


\section{Crime}
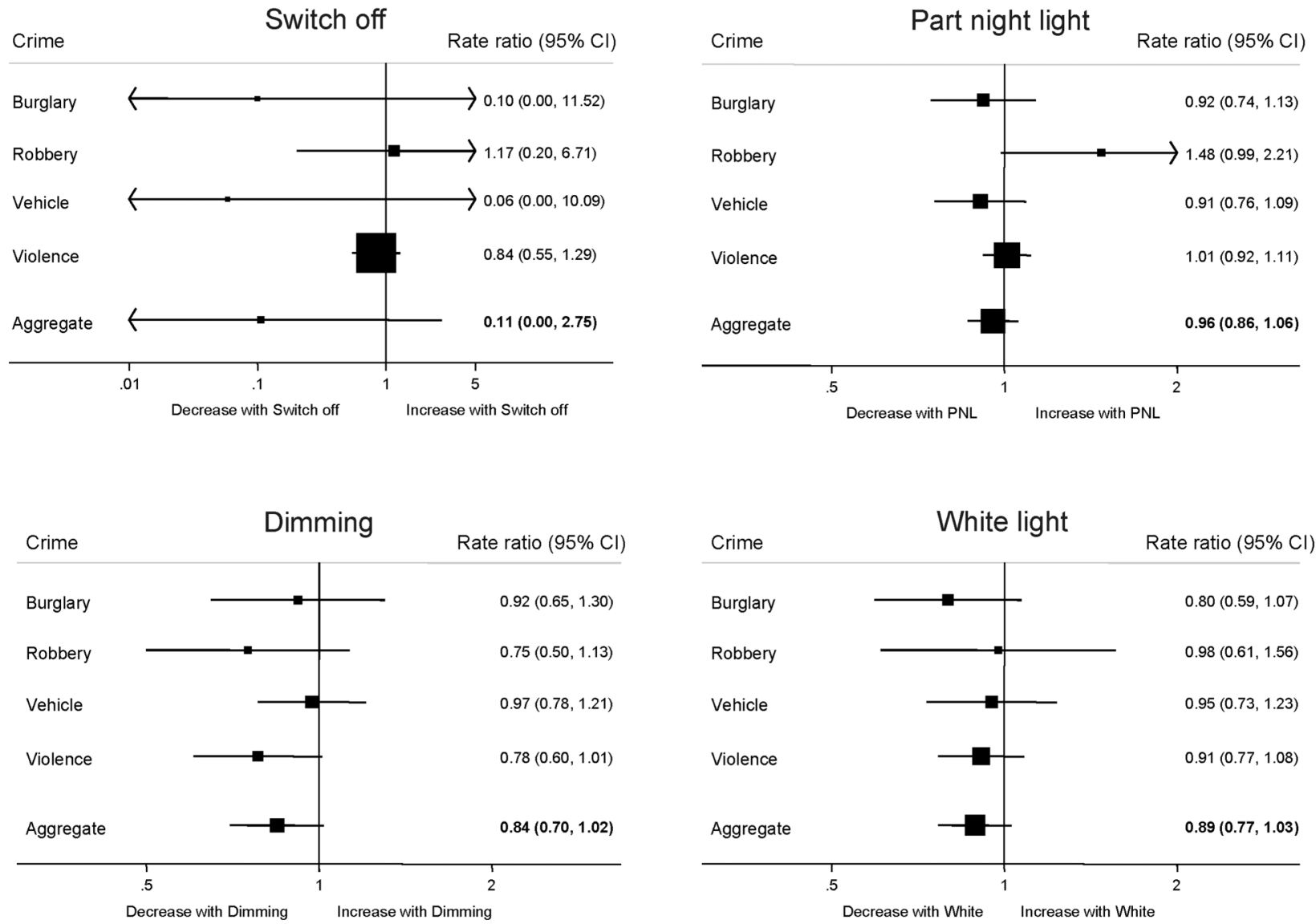

Figure 4 Associations between street light adaptation strategies and crime.

\section{DISCUSSION}

The results provide no evidence that switch off, part-night lighting, dimming, or white light adaptations to street lighting were associated with night-time traffic collisions. The results also provide no evidence that these lighting strategies are associated with an increase in crime at an area level. Results suggest that in the aggregate, dimming and white light regimes were associated with reductions in crime, though estimates were imprecise.

\section{Limitations}

Selection bias: this study was able to obtain usable data on street lighting changes from 62 of 174 local authorities. It is possible that local authorities may have declined to participate because of expected or known increases in collisions or crime in their areas due to lighting changes. If changes in collisions or crime are greater in the non-participating authorities, our study may have underestimated the effects of reduced lighting on collisions and crime.

Information bias: our study used routine data sources on road traffic collisions and crime. These data sets have several limitations; in particular, they may be incomplete due to underreporting of incidents. However, for under-reporting to affect the results of our analysis this would require differential changes over time in the recording of crime and collisions in the streets where lighting has been changed, compared with streets without changes to street lighting, which seems unlikely.

To address the potential for under-reporting to bias estimates of effect on collisions, we analysed separately those collisions where casualties were fatally or seriously injured, as these collisions are more likely to be reported to the police. These analyses found no evidence for associations between street lighting changes and night-time collisions. We also analysed crimes that are more likely to be reported to the police (ie, burglary and vehicle theft reports are required for insurance claims). The estimated effects were not consistently larger for these two types of crime.

We were unable to specifically examine crime occurring at night using the Police.uk data. Our analyses were, however, limited to crimes that the crime survey of England and Wales suggests are more likely to occur in the evening or at night. It is unlikely that another data set would have been able to address this limitation, as the exact times of many offences (such as property or vehicle thefts) are unknown to victims. The Police.uk crime data have a further limitation: they are geographically obscured to protect the anonymity of victims. To address this, we analysed the data at an area level for which the spatial accuracy of the data is known to be good, ${ }^{13}$ though this diminished statistical power.

Confounding: We did not take into account the potential impact of other road safety or crime prevention initiatives, such as improved road markings, policing interventions, or CCTV. If such measures have been introduced more often in streets where lighting has been changed than elsewhere, it is possible that some of the changes in crime in areas where lighting has been changed may be attributable to these other measures.

Despite the limitations of this study, we utilised two large publicly available data sets to provide evidence on the relationship between recent street lighting adaptation strategies, road traffic collisions and crime. Systematic reviews of the evidence on the effects of increased street lighting on road traffic collisions and 
crime suggest relative reductions of $32 \%$ and $38 \%$, respectively. ${ }^{10}{ }^{11}$ The current study showed CIs sufficiently narrow to exclude changes in collisions of such magnitude. The results for crime were highly heterogeneous and limited in power due to the need to aggregate to MSOA level, but the average effects estimated overall do not suggest any increase in crime at an area level with reduced lighting. Again, CIs were sufficiently narrow to exclude an increase in crime of such magnitude as may have been expected. The estimates for switch off, however, are imprecise because of the small number of areas in which switch off was implemented, and so should be treated with caution.

\section{Interpretation}

Despite using 14 years of data on road traffic collisions in 62 local authorities, we found no convincing evidence for associations between street lighting adaptations and road traffic collisions. As we have no direct measures of the number of trips taken, or modes of travel before and after implementation of street lighting interventions, we cannot know whether this reflects reduced mobility or changes in mode (eg, from walking to car travel) in areas where either switch off or part-night lighting had been implemented. It is possible that the numbers of pedestrians, cyclists, motorcyclists and car drivers who travel within the streets where street lighting was reduced declined at the same time as the lighting was reduced, resulting in fewer collisions in those streets. If so, any increase in hazards to road users due to lower lighting conditions may have been obscured by a reduction in numbers of people exposed to road injury risk at night. However, qualitative and survey evidence ${ }^{3}{ }^{16}$ suggests that changes to mobility overall, and mode choice in areas affected were likely to be minimal.

This study did, however, suggest an association between some street lighting adaptations and crime. While there was significant statistical heterogeneity in effects estimated at police force level, results overall were suggestive of an association between dimming and reductions in crime, particularly for violent crime. These results may lend support to the hypothesis linking lower levels of visibility to difficulties in identifying 'suitable' targets from those on the street at night. Results also suggested an association between white light and reductions in crime, particularly burglary, which may provide support for the credibility of mechanisms linking increased visibility or increased investment in local communities to reductions in crime. If reduced street lighting displaces pedestrian activity to better-lit streets, this might reduce the risks of victimisation and interpersonal crime on those streets, and increase guardianship on the better-lit streets. Different causal mechanisms may apply in different contexts, and these need to be assessed by further research.

This study does not support concerns around impacts of switchoff, part-night lighting, dimming and white light on crime and road safety. Local authorities informally (and sometimes formally) assess risks when adapting street lighting in local areas, drawing on local experiments and trials, ${ }^{17}$ and national and professional guidance on the selection of lighting classes. ${ }^{12}$ Considerations of the appropriate 'lighting class' for roads reflect a number of factors, including speed limits, traffic volume, composition of motorised versus non-motorised traffic, junction density, presence of parked vehicles, ambient luminosity (lighting from other sources such as shops), and how easy the road is to navigate. ${ }^{1}$ Results from this study suggest that when risks are carefully considered, local authorities can safely reduce street lighting saving both costs and energy using switch off, part-night lighting, dimming, and white light strategies without necessarily impacting negatively upon road traffic collisions and crime. The participating local authorities included a good range of communities in terms of population density, geographic location, and economic resources. Our results may, therefore, be generalisable to other communities considering street lighting reduction strategies.

This study was able to shed light on the impact of reduced street lighting at night. More research is needed on how different lighting regimes affect opportunities for crime and crime prevention, and on other public health impacts of changes in light at night, given the suggestive evidence that artificial light may be linked to health outcomes as diverse as obesity, ${ }^{7}$ sleep and cancer. ${ }^{8}$

\section{What is already known on this subject}

- There is evidence that introducing street lighting at night is associated with reductions in road traffic crashes and crime.

- Many local authorities in England and Wales are reducing street lighting at night to save energy costs and reduce carbon emissions.

\section{What this study adds}

- There is no evidence that reduced street lighting is associated with increases in road traffic collisions or crime.

- Dimming the amount of light or switching to white light/ LEDs may reduce crime in an area.

- When risks are carefully considered, local authorities can safely reduce street lighting, saving energy costs and reducing carbon emissions, without impacting negatively on traffic collisions and crime.

Acknowledgements The authors wish to acknowledge the advice and support of the Institution of Lighting Professionals and the London Lighting Engineers Group. The authors thank the members of the project advisory group: Denise Kendrick, Emily Conner and Mark Norris for their advice throughout the project, and the local authority street lighting managers who provided data for the project.

Contributors All authors contributed to the design of the study and the writing of the manuscript. RS, CP and LT collected, managed and linked the GIS and outcome data. CG provided advice on data management. RS, BA and PE conducted the statistical analysis. SJ advised on analysis of crime data.

Funding The LANTERNS project was funded by the National Institute for Health Research (NIHR) Public Health Programme (project number 11/3004/02). The views and opinions expressed in this report are those of the authors and do not necessarily reflect those of the Department of Health.

Competing interests None declared.

Provenance and peer review Not commissioned; externally peer reviewed.

Open Access This is an Open Access article distributed in accordance with the Creative Commons Attribution Non Commercial (CC BY-NC 4.0) license, which permits others to distribute, remix, adapt, build upon this work non-commercially, and license their derivative works on different terms, provided the original work is properly cited and the use is non-commercial. See: http://creativecommons.org/ licenses/by-nc/4.0/

\section{REFERENCES}

1 British Standards Institution. BS 5489 Code of practice for the design of road lighting. Lighting of roads and public amenity areas. London: British Standards Institution, 2013.

2 Institution of Lighting Professionals. PLG 08: guidance on the application of adaptive lighting within the public realm. Professional lighting guide. Rugby, Warwickshire: ILP, 2013 


\section{Other topics}

3 Perkins C, Steinbach R, Tompson L, et al. What is the effect of reduced street lighting on crime and road traffic injuries at night? A mixed methods study. Report submitted to the National Institute for Health Research, 2015.

4 Automobile Association. Turning off street lights: inquests reveal pattern of death on councils' blacked out roads. Automobile Association, 2014.

5 House of Commons on Science and Technology. Light pollution and astronomy. London: The Stationary Office, 2003.

6 Falchi $F$, Cinzano $P$, Elvidge $C D$, et al. Limiting the impact of light pollution on human health, environment and stellar visibility. J Environ Manage 2011;92:2714-22.

7 McFadden E, Jones ME, Schoemaker MJ, et al. The relationship between obesity and exposure to light at night: cross-sectional analyses of over 100,000 women in the breakthrough generations study. Am J Epidemiol 2014;180:245-50.

8 Navara KJ, Nelson RJ. The dark side of light at night: physiological, epidemiological, and ecological consequences. J Pineal Res 2007;43:215-24.

9 Shuboni D, Yan L. Nighttime dim light exposure alters the responses of the circadian system. Neuroscience 2010;170:1172-8.

10 Beyer F, Ker K. Street lighting for preventing road traffic injuries. Cochrane Database Syst Rev 2009;(1):CD004728.
11 Welsh B, Farrington D. Effects of improved street lighting on crime. Campbell Sys Rev 2008;13:1-51.

12 OS MasterMap Integrated Transport Network Layer [Shapefile geospatial data], Coverage: England and Wales, Updated Nov 2013, Ordnance Survey, GB. Using: EDINA Digimap Ordnance Survey Service, <http://edina.ac.uk/digimap>, Downloaded: Dec 2013.

13 Tompson L, Johnson S, Ashby M, et al. UK open source crime data: accuracy and possibilities for research. Cartogr Geogr Info Sci 2014:42:2:97-111.

14 Home Office. British crime survey, 2007-2008. Home Office, 2009.

15 Armstrong B, Gasparrini A, Tobias A. Conditional Poisson models: a flexible alternative to conditional logistic case cross-over analysis. BMC Med Res Methodol 2014; $14: 122$

16 Green J, Perkins C, Steinbach R, et al. Reduced street lighting at night and health: a rapid appraisal of public views in England and Wales. Health Place 2015;34: $171-80$.

17 Shaw R. Streetlighting in England and Wales: new technologies and uncertainty in the assemblage of streetlighting infrastructure. Environ Plann $A$ 2014;46:2228-42. 